OPEN ACCESS

Edited by:

Takao K. Hensch,

Harvard University, United States

Reviewed by:

Kasia M. Bieszczad,

Rutgers University, The State

University of New Jersey,

United States

Nicoletta Berardi,

Italian National Research Council

(CNR), Italy

*Correspondence:

Eve-Marie Quintin

eve-marie.quintin@mcgill.ca

Received: 15 December 2018

Accepted: 16 July 2019

Published: 18 September 2019

Citation:

Quintin E-M (2019) Music-Evoked

Reward and Emotion: Relative

Strengths and Response to Intervention of People With ASD.

Front. Neural Circuits 13:49.

doi: 10.3389/fncir.2019.00049

\section{Music-Evoked Reward and Emotion: Relative Strengths and Response to Intervention of People With ASD}

\author{
Eve-Marie Quintin* \\ Department of Educational and Counselling Psychology, McGill University, Montreal, QC, Canada
}

This review presents research findings showing that music is a unique domain to assess perception, reward, emotion, and associated physiological reactions and neural circuitry of people with autism spectrum disorder (ASD). There is growing evidence, reported in several studies in this review article, indicating that music is a relative strength of people with ASD including musical pitch perception, musical memory, and identification of music-evoked emotions. Listening to music activates neural circuits of reward and emotion response, which are described. Research presented shows adults with ASD also activate these systems when listening to music, although there may be developmental differences in the physiological and neural response to music in childhood and adolescence alongside typical behavioral response. Nonetheless, studies reviewed lend support to the use of music therapy and education for people with ASD, specifically to improve social skills and communication. Neural correlates of response to music therapy and education are also discussed. Taken together, findings reviewed provide evidence for music as a strength-based approach for ASD to assess reward and emotion response and as a powerful tool for intervention.

Keywords: autism spectrum disorder, reward, emotion, music, perception, brain development

\section{THE SOCIAL ROLE OF MUSIC}

Music-making is part of the history of the human race. In 1995, paleontologist Ivan Turk found a 43,000-82,000 year old bone with characteristic wholes, which many believe to have been a flute (Wong, 1997). This archeological evidence found in northwestern Slovenia suggests that music-making dates back at least to the times of Neanderthals (Huron, 2001). Although the meaning and use of music can vary between cultures and social context, music has a universal and unique social and cultural role (Cross, 2001). Closely related to its social role, music is a powerful medium to convey emotions (Meyer, 1956). The fact that emotions are communicated through music is one of the reasons people listen to music and why people report that music listening is rewarding (Juslin and Sloboda, 2001).

\section{PHYSIOLOGICAL AND NEURAL REWARD RESPONSE TO MUSIC}

Listening to music is often reported as a pleasurable experience among lists of everyday experiences that people enjoy engaging in (Dubé and Le Bel, 2003). Some people even report intense euphoria when listening to emotionally intense and very pleasant music, also known as "musical chills" (Goldstein, 1980; Panksepp, 1995). 
Subjective ratings of musical chills are associated with a characteristic physiological response of autonomic nervous system arousal including increase in heart rate, respiration depth (Blood and Zatorre, 2001; Salimpoor et al., 2011), electromyogram signal (Blood and Zatorre, 2001), electrodermal response, and decreased temperature and blood volume pulse amplitude (Salimpoor et al., 2011). At the neural level, PET and fMRI studies showed that musical chills are associated with activity in several regions including the hypothalamus, which may point to pleasant music eliciting an autonomic response given its role in controlling heart rate and respiration (Menon and Levitin, 2005), the nucleus accumbens (NAc) and ventral tegmental area (VTA), which suggests occurrence of a reward response (Blood and Zatorre, 2001; Menon and Levitin, 2005), and of the left amygdala (Blood and Zatorre, 2001), which is associated with processing of music-evoked emotions along with the NAc and hypothalamus (Koelsch, 2014). The NAc and VTA are part of the dopaminergic reward response system for stimuli that elicit intense emotions and pleasure such as food, monetary reward, and certain psychoactive drugs (Egerton et al., 2009). A study combining $\left[{ }^{11} \mathrm{C}\right]$ raclopride PET and fMRI showed increase in endogenous dopamine transmission involving the right NAc during musical chills, and the right caudate nucleus in anticipation of these moments, thus confirming that listening to pleasurable music activates the dopaminergic reward system (Salimpoor et al., 2011).

\section{MUSIC AND AUTISM SPECTRUM DISORDER (ASD)}

As per the fifth edition of the Diagnostic and Statistical Manual of Mental Disorders, autism spectrum disorder (ASD) is defined as "persistent deficits in social communication and social interaction across multiple contexts [and] restricted, repetitive patterns of behavior, interests, or activities" (American Psychiatric Association, 2013). Knowledge of genetic risk factors associated to neurological development and to ASD is constantly improving thanks to advances in genetic techniques (WoodburySmith and Scherer, 2018) such as induced pluripotent stem cells derived neurons (Zaslavsky et al., 2019). At a behavioral level, there is growing interest in the strengths associated with ASD (Mottron et al., 2006). There is growing evidence that music perception and ability are one of the relative strengths of people with ASD; relative to their difficulties (Heaton, 2009). Although research on music and ASD has been flourishing since the 1990s, the idea that music is a strength within the ASD profile dates back to Kanner (1943). He described 11 children with ASD including six children with a particular musical interest or ability. In a now seminal study, Heaton et al. (1998) taught children with ASD to associate syllables or musical notes (pitches) with pictures of an animal. One week later, children with ASD and a comparison group with typical development matched for mental age remembered syllables equally well but the group of children with ASD showed more accurate memory for pitches (Heaton et al., 1998). A more recent study has extended this finding, showing that it also holds for memory of musical melodies (Stanutz et al., 2014). Further, children with ASD can easily label each pitch when several pitches are played together in a musical chord, known as chord segmentation, when they have been previously exposed to individual pitches (Heaton, 2003). People with ASD also display enhanced recognition of alterations of single pitches in a melody, even when the altered note remains in tune with the scale of the melody such that most people would not detect this type of alteration (Mottron et al., 2000). Similarly, they can distinguish between two interleaved melodies played at the same frequency, which are melodies played simultaneously but organized such that notes of one melody do not co-occur with the notes of the other melody (Bouvet et al., 2016). Enhanced pitch perception is an example of perceptual strengths of people with ASD that Mottron et al. (2014) suggest to stem from brain plasticity and reorganization triggered by genetic factors, which also lead to reduced socialization.

People with ASD also show enhanced discrimination of changes of less than a semitone, the smallest interval between two pitches in western music (Bonnel et al., 2010), and discrimination of similar sound frequencies (e.g., noticing the difference between $1,000 \mathrm{~Hz}$ vs. $1,030 \mathrm{~Hz}$; Bonnel et al., 2003). Bhatara et al. (2013a) also found typical discrimination of pitches at 500 and $1,000 \mathrm{~Hz}$, but do not at 4,000 Hz. Thus, a perceptual enhancement may be specific to detecting small pitch changes and changes at low frequencies $(<4,000 \mathrm{~Hz})$. It has also been suggested that enhanced auditory discrimination is present in only $20 \%$ of people with ASD (Jones et al., 2009), which could explain mixed findings in studies with small sample sizes. Further, we wonder if modifying experimental paradigms to allow more time for participants to respond would have lead to different results because people with ASD showed delayed auditory response of $11 \mathrm{~ms}$ as measured with MEG response of the superior temporal gyrus to sound frequencies below $1,000 \mathrm{~Hz}$ (Roberts et al., 2010). Such a delay may explain why adolescents with ASD are not as accurate as those with typical development at processing small gaps (in milliseconds) of silence between tones (Bhatara et al., 2013a) and why adults with ASD are less accurate than typically developing peers at judging duration of auditory events (Kargas et al., 2015). However, despite potential differences in perception of specific sound frequencies and in timing perception at the millisecond level, children and adolescents with ASD can accurately judge duration of musical events (Jones et al., 2009), perceive meter in western music (DePape et al., 2012), and are able to create and replicate musical melodies with coherent musical structure in a similar amount of time as typically developing peers (Quintin et al., 2013).

Furthermore, adolescents with ASD show as much interest in music and spend as many hours per week listening to music as typically developing peers, as revealed by both self and parent report (Bhatara et al., 2013b). Adults with ASD also report listening to music for similar reasons as typical listeners including to relax or to cheer up or feel better (Allen et al., 2009), indicating that music listening is a rewarding activity for people with ASD, and may thus activate the dopaminergic response system, in part due to its effect on emotions and mood regulation. Indeed, typical recognition of music-evoked emotions has been reported on several occasions. Children with ASD can accurately 
identify happy, sad (Heaton et al., 1999; Quintin et al., 2011), scary, and peaceful music (Quintin et al., 2011). They can also associate images of social scenes depicting an emotion with a corresponding musical excerpt (Heaton et al., 2008).

The connection between music and ASD lead Bergmann et al. $(2015,2016)$ to develop the Music-based Scale for Autism Diagnosis (MUSAD), conceived as a musical equivalent of the Autism Diagnostic Observation Schedule (ADOS-2; Lord et al., 2012). The MUSAD consists of several joint music-making activities during which social interactions and stereotyped, restricted, and repetitive behaviors can be prompted, observed, and quantified. Given that joint music making elicits nonverbal communication, the MUSAD can inform the differential diagnosis between ASD and intellectual developmental disorders with minimally verbal older adults who do not have the language skills to complete the advanced modules of the ADOS-2 and for whom the materials of the lower modules are not age appropriate (Bergmann et al., 2015, 2016).

\section{PHYSIOLOGICAL AND NEURAL RESPONSE TO MUSIC AND ASD}

Despite relative strengths in music perception, there may be developmental differences in response to music-evoked emotions. Children and adolescents (Stephenson et al., 2016) and adults (Allen et al., 2013) with ASD can accurately recognize music-evoked emotions. However, Stephenson et al. (2016) reported that children and adolescents had lower skin conductance response than typically developing peers when listening to music, while the two groups showed similar baseline skin conductance during a visual task. In contrast, Allen et al. (2013) did not find signs of reduced skin conductance when adults with ASD listened to the same music used by Stephenson et al. (2016) as compared to listening to environmental noise or silence. Taken together, these findings may suggest that ASD is associated with a unique developmental trajectory of physiological response to music evoked-emotions perhaps affecting embodied cognition, the relevance and salience of environmental stimuli (Klin et al., 2003), and neural and behavioral development (Rosenberg et al., 2015). In Allen et al.'s (2013) study, participants with ASD listed fewer words than a comparison group of typical adults when asked to describe music-evoked emotions, which was accounted for by the presence of type II alexithymia symptoms in the ASD group. In other words, adults with ASD "feel" music-evoked emotions but explain what they feel in few words.

Neuroimaging studies can also explain the relationship between physiological and behavioral responses to music-evoked emotions. Adults with ASD show typical behavioral continuous ratings (very sad to very happy; Gebauer et al., 2014) and valence (negative to positive) and arousal (low to high energy) ratings (Caria et al., 2011) accompanied by overall typical neural processing of music including auditory and motor areas and activation of regions involved in the dopaminergic reward response system (Caria et al., 2011; Gebauer et al., 2014) to "musical chills" as described above (Blood and Zatorre, 2001;
Menon and Levitin, 2005; Salimpoor et al., 2011). Specifically, contrasting activation for happy or sad music to chromatic scales (neutral stimuli) revealed activation of ventral striatum and NAc for adults with ASD, as was the case for adults in a typical comparison group (see reproduction of Figure 1 from Gebauer et al., 2014). Considering participants' musical preference revealed that adults with ASD showed activation of the medial prefrontal cortex when listening to preferred happy music, of the VTA for preferred sad music, and of the caudate nucleus for preferred and non-preferred happy music (Caria et al., 2011). Processing of music-evoked emotions was also associated with activation of medial orbitofrontal cortex and limbic and paralimbic areas extending into the amygdala (Gebauer et al., 2014). Music thus activates typical reward and emotion processing systems of people with ASD. However, the insula, an area associated to awareness and cognitive processing of emotional states, showed both hyper(see reproduction of Figure 2 from Gebauer et al., 2014) or hypo-activation (Caria et al., 2011). This mixed finding may be related to the fact that novel music was presented in one study (Gebauer et al., 2014) while well-known and participant selected music was used in the other (Caria et al., 2011). Alternatively, conscious awareness of musicevoked emotions may vary more for adults with ASD than without ASD.

Neuroimaging studies of music and ASD with children have mainly assessed neural response to songs and speech, without an emphasis on emotions. Children with ASD show typical recruitment of auditory areas when processing songs (Lai et al., 2012; Sharda et al., 2015). However, when listening to songs compared to speech, they show greater activation in left inferior frontal gyrus and posterior brain areas and increased functional

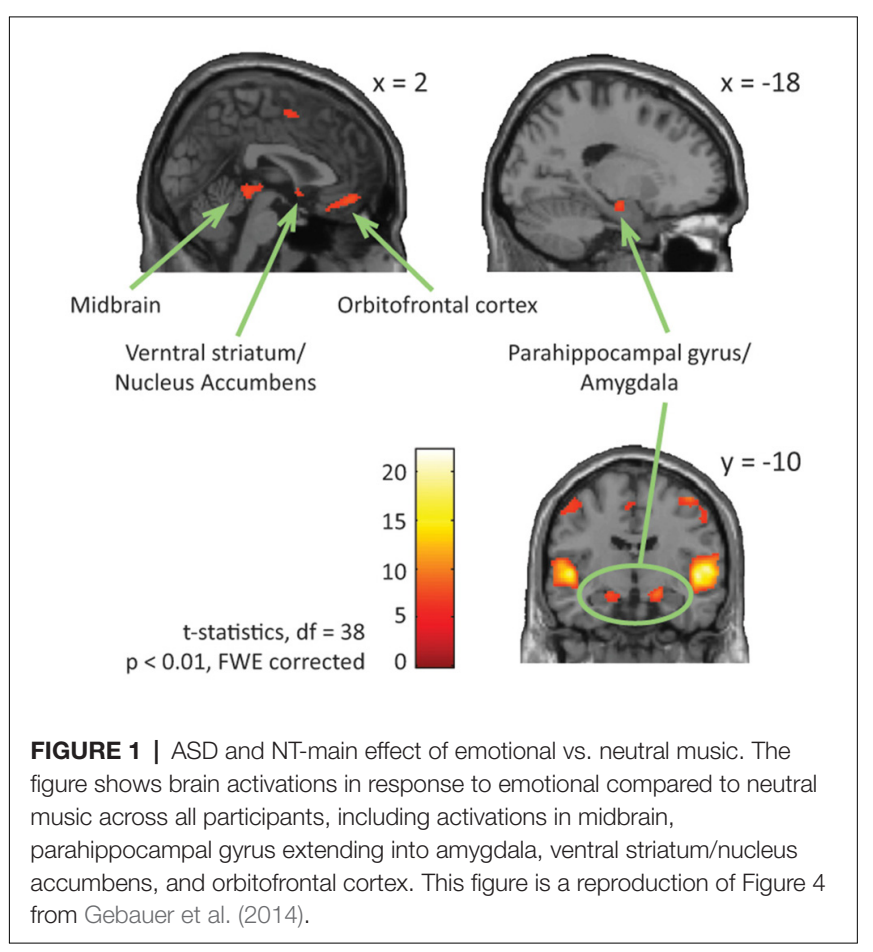




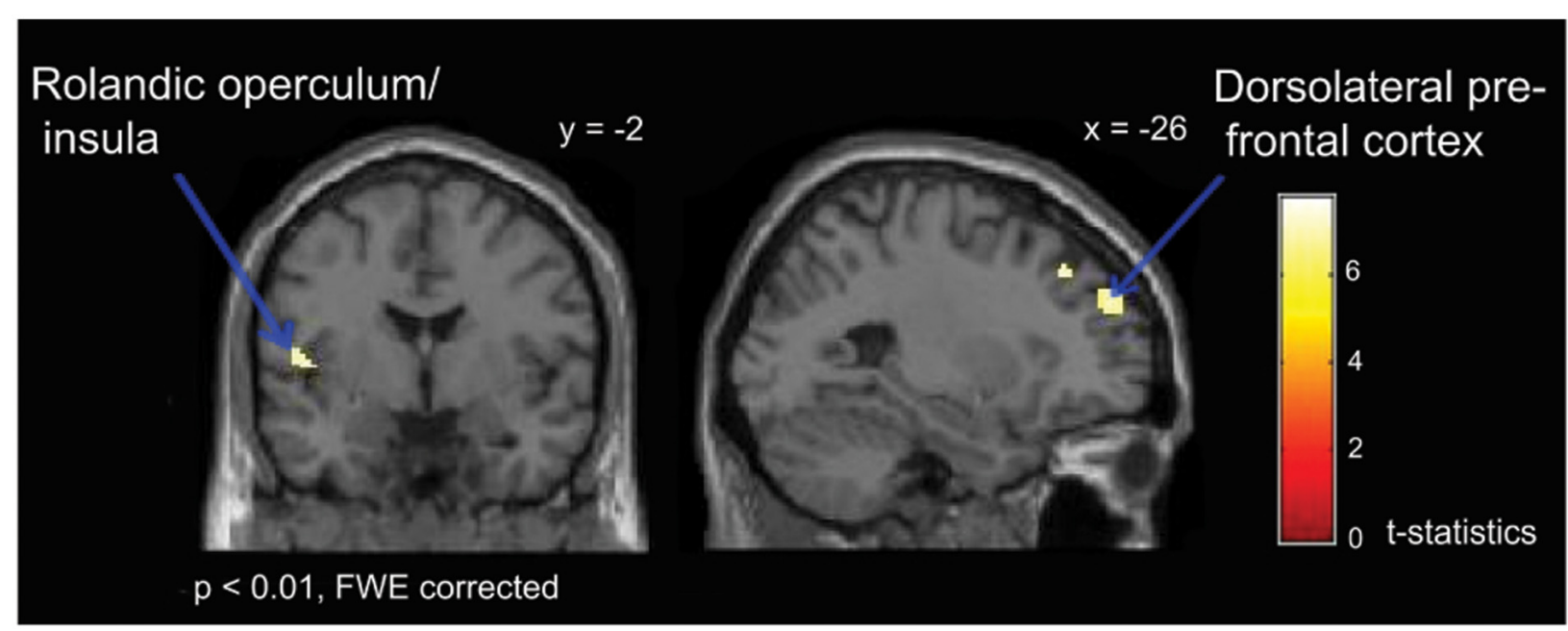

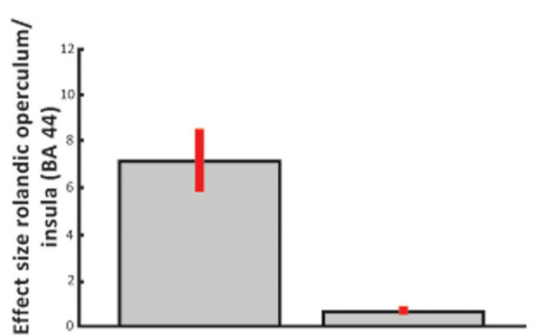

ASD

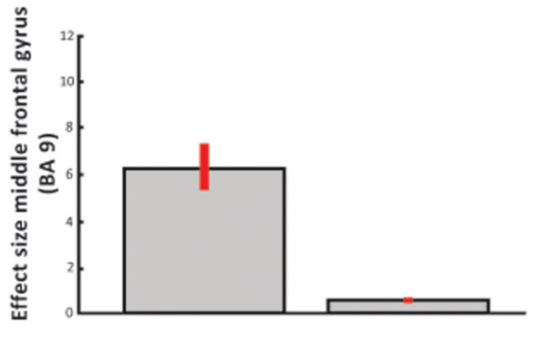

ASD

NT

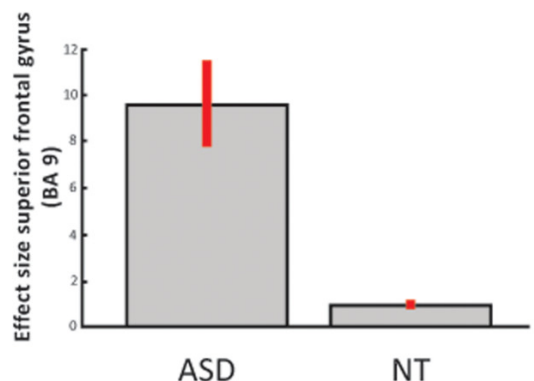

FIGURE 2 | ASD > NT: group difference for happy vs. sad music (FWE p < 0.01). Individuals with ASD showed increased activation in dorsolateral prefrontal cortex, i.e., middle and superior frontal gyrus, and in insula/rolandic operculum. Box plots show mean effect size for each group in the peak voxel for each region, with $95 \%$ confidence intervals. This figure is a reproduction of Figure 3 from Gebauer et al. (2014).

connectivity between left inferior frontal gyrus and superior temporal gyrus and between frontal and posterior areas (Lai et al., 2012). Similarly, Sharda et al. (2015) found greater connectivity of the left inferior frontal gyrus with bilateral posterior temporal, right parieto-occipital, and right cerebellar regions when children with ASD listen to sung compared to spoken words. These findings suggest that although frontotemporal circuits are involved in processing both speech and song, these circuits seem more responsive to processing songs for children with ASD perhaps due to changes in pitch occurring slower in songs than in speech (Lai et al., 2012). Listening to music and songs is thus a rewarding experience and powerful medium to communicate emotions for many people including people with ASD.

\section{MUSIC THERAPY AND ASD AND MUSIC EDUCATION IN THE GENERAL POPULATION}

Given the musical strengths of children and adolescents with ASD, many families engage their child with ASD in music therapy, which can improve social outcomes (LaGasse, 2017; see Table 1). "Music therapy techniques include free and structured improvisation, singing songs and vocalization, and listening to both pre-recorded and live music" leading to nonverbal musical interactions between the participant and therapist that scaffold learning to communicate, partake in social interaction, and express emotions through music (Geretsegger et al., 2014). A review of 10 studies showed that music therapy can improve social interaction, verbal communication, initiating behavior, and social-emotional reciprocity (Geretsegger et al., 2014). However, a large randomized clinical trial including nine countries did not find effects of improvisational music therapy on social skills measured with the ADOS social affect domain and Social Responsiveness Scale (SRS; Bieleninik et al., 2017). Sharda et al. (2018) also failed to find changes in the SRS-2 associated with music therapy for ASD, but reported that music therapy improves communication and quality of life. Further, improvements in communication were associated with increased auditory-subcortical and decreased auditoryvisual functional brain connectivity. Taken together, these studies show the importance of choice of outcome measures for assessing the effects of music therapy and show that it can have positive effects on social and communicative skills of children with ASD. Whether these effects are comparable to those of social skills intervention programs such as the PEERS (Laugeson et al., 2015) and JASPER (Kasari et al., 2015) programs 
TABLE 1 | Findings of studies on the effects of music therapy for autism spectrum disorder (ASD).

\begin{tabular}{|c|c|}
\hline Reference & Main findings \\
\hline Sharda et al. (2018) & $\begin{array}{l}\text { Improvements in communication skills associated with resting stage auditory-subcortical and auditory-fronto-motor } \\
\text { brain connectivity. }\end{array}$ \\
\hline Mössler et al. (2019) & Improvements in social skills, communication, and language are associated with the quality of the relationship with the therapist. \\
\hline Bieleninik et al. (2017) & No significant difference in improvement of ASD symptom severity. \\
\hline Carpente (2016) & Improvements in self-regulation, engagement, communication. \\
\hline Ghasemtabar et al. (2015) & Improvements in social skills. \\
\hline LaGasse (2014) & $\begin{array}{l}\text { Improvements in joint attention with peers, eye gaze towards persons; no improvements in initiation or response to communication } \\
\text { or social withdrawal. }\end{array}$ \\
\hline Thompson et al. (2014) & $\begin{array}{l}\text { Improvements in social interactions in the home, quality of parent-child relationship (this is a study of family-centered music therapy); } \\
\text { no improvements in language skills or general social responsiveness. }\end{array}$ \\
\hline Gattino et al. (2011) & $\begin{array}{l}\text { Improvements in nonverbal communication for autism subgroup, but no improvements in nonverbal, verbal, and social } \\
\text { communication for all participants combined. }\end{array}$ \\
\hline Hillier et al. (2012) & Improvements in self-esteem, attitude towards peers, reduced anxiety. \\
\hline Kim et al. (2009) & Improvements in emotional synchrony, initiation of engagement, compliance with music therapist, and displaying joy. \\
\hline Kim et al. (2008) & Improvements in joint attention behaviors, nonverbal social communication, eye contact, and turn-taking. \\
\hline Boso et al. (2007) & Decrease of ASD and psychiatric symptoms. \\
\hline Kern and Aldridge (2006) & Facilitation of play and interaction with peers; no improvements in social skills. \\
\hline Ma et al. (2001) & Improvement in communication skills. \\
\hline
\end{tabular}

This table includes peer-reviewed studies on music therapy for ASD published since 2000. This table does not include studies where music is incorporated to therapy (e.g., adding music to speech therapy or to $A B A$ intervention).

or theatre interventions (Corbett et al., 2016) remains to be established.

Music education for ASD has not been studied as extensively as music therapy and holds promise to have positive effects given that music is one of their relative strengths. The main goal of music education is to develop musical skills, knowledge, and abilities, and often follows a set curriculum (Salvador and Pasiali, 2017). The focus is to gain musical performance skills, while music therapy targets personal development (Salvador and Pasiali, 2017). Music education in the general population is associated with improvements that transfer to enhanced non-musical skills including near transfer to working memory (Bailey and Penhune, 2010) and executive functioning (Moreno et al., 2011), that are practiced when learning to play an instrument or learning to sign, and far transfer to verbal skills (Schellenberg, 2004, 2011) and verbal memory (Ho et al., 2003; Roden et al., 2012), likely because mechanisms involved in music and speech processing overlap (Patel, 2011, 2014). As such, musical training leads to greater improvements in language skills and executive functions than visual art training (Moreno et al., 2011). Further, the use of music in speech therapies for ASD is associated with positive outcomes and increased language gains (Lim and Draper, 2011; Chenausky et al., 2016). In addition, music education of typically developing children and adolescents has been shown to result in brain plasticity, as exemplified by shorter delays in neural response to speech sounds in noise (Kraus and Strait, 2015), increased neural discrimination of small pitch changes in speech (Carpentier et al., 2016) and of spoken syllables (Kraus et al., 2014), enhanced neural correlates of executive functioning (Moreno et al., 2011), and enlargement of brain areas associated with music perception including the auditory cortex and limbic areas (Hyde et al., 2009); with studies including comparisons of music education to physical fitness (Kraus and Strait, 2015), visual arts training (Moreno et al., 2011), second language instruction (Carpentier et al., 2016), exposure to musical instruments without formal instruction
(Hyde et al., 2009), and longitudinal investigations of effects of music education over time (Kraus et al., 2014). It is also worth noting that music education is related to enhanced visualperceptual skills (Schellenberg, 2004, 2011) and that joint musicmaking promotes social skills (Kirschner and Tomasello, 2010; Rabinowitch and Meltzoff, 2017).

In sum, music therapy can have a positive impact on social and communication skills of children and adolescents with ASD while music education holds the potential to improve their working memory, executive functioning and language skills. Individualized interventions should include music therapy or education or their combination depending on intervention goals. The fields of music therapy and education may have much to gain from merging their approaches.

\section{SUMMARY}

Musical ability and interest are relative strengths of people with ASD including enhanced musical memory, enhanced or typical perception of pitches and sound frequencies, and typical perception of music-evoked emotions. When listening to music, adults with ASD show typical activation of neural circuitry associated with reward and emotion processing including NAc, VTA, ventral striatum, amygdala, medial prefrontal and orbitofrontal cortex. Adults with ASD also have a typical galvanic skin response to music-evoked emotions, but this response seems decreased in children and adolescents with ASD. In contrast, fronto-temporal circuits of children with ASD are particularly responsive to songs. There may thus be different physiological and neural developmental trajectories in response to a few aspects of music, but overall typical processing, alongside typical behavioral response to music-evoked emotions among people with ASD. Music is a powerful therapeutic and educational tool for people with ASD, with research showing improvements in social and communicative skills associated with music therapy. The growing field of music and ASD research holds promise for 
revisiting our understanding of social and emotional profiles of people with ASD and providing strength-based interventions.

\section{AUTHOR CONTRIBUTIONS}

The author confirms being the sole contributor of this work and has approved it for publication.

\section{REFERENCES}

Allen, R., Davis, R., and Hill, E. (2013). The effects of autism and alexithymia on physiological and verbal responsiveness to music. J. Autism Dev. Disord. 43, 432-444. doi: 10.1007/s10803-012-1587-8

Allen, R., Hill, E., and Heaton, P. (2009). 'Hath charms to soothe ...': an exploratory study of how high-functioning adults with ASD experience music. Autism 13, 21-41. doi: 10.1177/1362361307098511

American Psychiatric Association. (2013). "Neurodevelopmental disorders," in Diagnostic and Statistical Manual of Mental Disorders. Available online at https://doi.org/10.1176/appi.books.9780890425596.dsm01.

Bailey, J. A., and Penhune, V. B. (2010). Rhythm synchronization performance and auditory working memory in early- and late-trained musicians. Exp. Brain Res. 204, 91-101. doi: 10.1007/s00221-010-2299-y

Bergmann, T., Sappok, T., Diefenbacher, A., Dames, S., Heinrich, M., Ziegler, M., et al. (2015). Music-based Autism Diagnostics (MUSAD) - a newly developed diagnostic measure for adults with intellectual developmental disabilities suspected of autism. Res. Dev. Disabil. 43-44, 123-135. doi: 10.1016/j.ridd. 2015.05.011

Bergmann, T., Sappok, T., Diefenbacher, A., and Dziobek, I. (2016). Music in diagnostics: using musical interactional settings for diagnosing autism in adults with intellectual developmental disabilities. Nord. J. Music Ther. 25, 319-351. doi: 10.1080/08098131.2015.1039567

Bhatara, A., Babikian, T., Laugeson, E., Tachdjian, R., and Sininger, Y. S. (2013a). Impaired timing and frequency discrimination in high-functioning autism spectrum disorders. J. Autism Dev. Disord. 43, 2312-2328. doi: 10.1007/s10803013-1778-y

Bhatara, A., Quintin, E. M., Fombonne, E., and Levitin, D. J. (2013b). Early sensitivity to sound and musical preferences and enjoyment in adolescents with autism spectrum disorders. Psychomusicology 23, 100-108. doi: 10.1037/a0033754

Bieleninik, L., Geretsegger, M., Mössler, K., Assmus, J., Thompson, G., Gattino, G., et al. (2017). Effects of improvisational music therapy vs enhanced standard care on symptom severity among children with autism spectrum disorder: the TIME-a randomized clinical trial. JAMA 318, 525-535. doi: 10.1001/jama. 2017.9478

Blood, A. J., and Zatorre, R. J. (2001). Intensely pleasurable responses to music correlate with activity in brain regions implicated in reward and emotion. Proc. Natl. Acad. Sci. U S A 98, 11818-11823. doi: 10.1073/pnas.1913 55898

Bonnel, A., McAdams, S., Smith, B., Berthiaume, C., Bertone, A., Ciocca, V., et al. (2010). Enhanced pure-tone pitch discrimination among persons with autism but not Asperger syndrome. Neuropsychologia 48, 2465-2475. doi: 10.1016/j. neuropsychologia.2010.04.020

Bonnel, A., Mottron, L., Peretz, I., Trudel, M., Gallun, E., and Bonnel, A. M. (2003). Enhanced pitch sensitivity in individuals with autism: a signal detection analysis. J. Cogn. Neurosci. 15, 226-235. doi: 10.1162/089892903321208169

Boso, M., Emanuele, E., Minazzi, V., Abbamonte, M., and Politi, P. (2007). Effect of long-term interactive music therapy on behavior profile and musical skills in young adults with severe autism. J. Altern. Complement. Med. 13, 709-712. doi: $10.1089 / \mathrm{acm} .2006 .6334$

Bouvet, L., Mottron, L., Valdois, S., and Donnadieu, S. (2016). Auditory stream segregation in autism spectrum disorder: benefits and downsides of superior perceptual processes. J. Autism Dev. Disord. 46, 1553-1561. doi: 10.1007/s10803-013-2003-8

Caria, A., Venuti, P., and de Falco, S. (2011). Functional and dysfunctional brain circuits underlying emotional processing of music in autism

\section{FUNDING}

This article is supported by research grants form the Social Sciences and Humanities Research Council of Canada, the Fonds de Recherche Québec Santé, and McGill University's William Dawson Scholar Program.

spectrum disorders. Cereb. Cortex 21, 2838-2849. doi: 10.1093/cercor/ bhr084

Carpente, J. A. (2016). Investigating the effectiveness of a developmental, individual difference, relationship-based (DIR) improvisational music therapy program on social communication for children with autism spectrum disorder. Music Ther. Perspect. 35, 160-174. doi: 10.1093/mtp/miw013

Carpentier, S. M., Moreno, S., and McIntosh, A. R. (2016). Short-term music training enhances complex, distributed neural communication during music and linguistic tasks. J. Cogn. Neurosci. 28, 1603-1612. doi: 10.1162/jocn_a_00988

Chenausky, K., Norton, A., Tager-Flusberg, H., and Schlaug, G. (2016). Auditorymotor mapping training: comparing the effects of a novel speech treatment to a control treatment for minimally verbal children with autism. PLoS One 11:e0164930. doi: 10.1371/journal.pone.0164930

Corbett, B. A., Key, A. P., Qualls, L., Fecteau, S., Newsom, C., Coke, C., et al. (2016). Improvement in social competence using a randomized trial of a theatre intervention for children with autism spectrum disorder. J. Autism Dev. Disord. 46, 658-672. doi: 10.1007/s10803-015-2600-9

Cross, I. (2001). Music, cognition, culture, and evolution. Ann. N Y Acad. Sci. 930, 28-42. doi: 10.1111/j.1749-6632.2001.tb05723.x

DePape, A. M., Hall, G. B., Tillmann, B., and Trainor, L. J. (2012). Auditory processing in high-functioning adolescents with Autism Spectrum Disorder. PLoS One 7:e44084. doi: 10.1371/journal.pone.0044084

Dubé, L., and Le Bel, J. (2003). The content and structure of laypeople's concept of pleasure. Cogn. Emot. 17, 263-295. doi: 10.1080/026999303 02295

Egerton, A., Mehta, M. A., Montgomery, A. J., Lappin, J. M., Howes, O. D., Reeves, S. J., et al. (2009). The dopaminergic basis of human behaviors: a review of molecular imaging studies. Neurosci. Biobehav. Rev. 33, 1109-1132. doi: 10.1016/j.neubiorev.2009.05.005

Gattino, G. S., Riesgo, R. D. S., Longo, D., Leite, J. C. L., and Faccini, L. S. (2011). Effects of relational music therapy on communication of children with autism: a randomized controlled study. Nord. J. Music Ther. 20, 142-154. doi: 10.1080/08098131.2011.566933

Gebauer, L., Skewes, J., Westphael, G., Heaton, P., and Vuust, P. (2014). Intact brain processing of musical emotions in autism spectrum disorder, but more cognitive load and arousal in happy vs. sad music. Front. Neurosci. 8:192. doi: $10.3389 /$ fnins.2014.00192

Geretsegger, M., Elefant, C., Mossler, K. A., and Gold, C. (2014). Music therapy for people with autism spectrum disorder. Cochrane Database Syst. Rev. 6:CD004381. doi: 10.1002/14651858.CD004381.pub3

Ghasemtabar, S. N., Hosseini, M., Fayyaz, I., Arab, S., Naghashian, H., and Poudineh, Z. (2015). Music therapy: an effective approach in improving social skills of children with autism. Adv. Biomed. Res. 4:157. doi: 10.4103/2277-9175 161584

Goldstein, A. (1980). Thrills in response to music and other stimuli. Physiol. Psychol. 8, 126-129. doi: 10.3758/bf03326460

Heaton, P. (2003). Pitch memory, labelling and disembedding in autism. J. Child Psychol. Psychiatry 44, 543-551. doi: 10.1111/1469-7610. 00143

Heaton, P. (2009). Assessing musical skills in autistic children who are not savants. Philos. Trans. R. Soc. Lond. B Biol. Sci. 364, 1443-1447. doi: 10.1098/rstb. 2008.0327

Heaton, P., Allen, R., Williams, K., Cummins, O., and Happé, F. (2008). Do social and cognitive deficits curtail musical understanding? Evidence from autism and Down syndrome. Br. J. Dev. Psychol. 26, 171-182. doi: $10.1348 / 026151007 \times 206776$ 
Heaton, P., Hermelin, B., and Pring, L. (1998). Autism and pitch processing: a precursor for savant musical ability? Music Percept. 154, 291-305. doi: $10.2307 / 40285769$

Heaton, P., Hermelin, B., and Pring, L. (1999). Can children with autistic spectrum disorders perceive affect in music? An experimental investigation. Psychol. Med. 29, 1405-1410. doi: 10.1017/s0033291799001221

Hillier, A., Greher, G., Poto, N., and Dougherty, M. (2012). Positive outcomes following participation in a music intervention for adolescents and young adults on the autism spectrum. Psychol. Music 40, 201-215. doi: $10.1177 / 0305735610386837$

Ho, Y. C., Cheung, M. C., and Chan, A. S. (2003). Music training improves verbal but not visual memory: cross-sectional and longitudinal explorations in children. Neuropsychology 17, 439-450. doi: 10.1037/0894-4105. 17.3.439

Huron, D. (2001). Is music an evolutionary adaptation? Ann. N Y Acad. Sci. 930, 43-61. doi: 10.1111/j.1749-6632.2001.tb05724.x

Hyde, K. L., Lerch, J., Norton, A., Forgeard, M., Winner, E., Evans, A. C., et al. (2009). Musical training shapes structural brain development. J. Neurosci. 29, 3019-3025. doi: 10.1523/JNEUROSCI.5118-08.2009

Jones, C. R., Happé, F., Baird, G., Simonoff, E., Marsden, A. J., Tregay, J., et al. (2009). Auditory discrimination and auditory sensory behaviours in autism spectrum disorders. Neuropsychologia 47, 2850-2858. doi: 10.1016/j. neuropsychologia.2009.06.015

Juslin, P. N., and Sloboda, J. A. (2001). Music and Emotion: Theory and Research. New York, NY: Oxford University Press.

Kanner, L. (1943). Autistic disturbances of affective contact. Nerv. Child 2, 217-250.

Kargas, N., López, B., Reddy, V., and Morris, P. (2015). The relationship between auditory processing and restricted, repetitive behaviors in adults with autism spectrum disorders. J. Autism Dev. Disord. 45, 658-668. doi: 10.1007/s10803014-2219-2

Kasari, C., Gulsrud, A., Paparella, T., Hellemann, G., and Berry, K. (2015). Randomized comparative efficacy study of parent-mediated interventions for toddlers with autism. J. Consult. Clin. Psychol. 83, 554-563. doi: $10.1037 / \mathrm{a} 0039080$

Kern, P., and Aldridge, D. (2006). Using embedded music therapy interventions to support outdoor play of young children with autism in an inclusive community-based child care program. J. Music Ther. 43, 270-294. doi: $10.1093 / \mathrm{jmt} / 43.4 .270$

Kim, J., Wigram, T., and Gold, C. (2008). The effects of improvisational music therapy on joint attention behaviors in autistic children: a randomized controlled study. J. Autism Dev. Disord. 38, 1758-1766. doi: 10.1007/s10803008-0566-6

Kim, J., Wigram, T., and Gold, C. (2009). Emotional, motivational and interpersonal responsiveness of children with autism in improvisational music therapy. Autism 13, 389-409. doi: 10.1177/13623613091 05660

Kirschner, S., and Tomasello, M. (2010). Joint music making promotes prosocial behavior in 4-year-old children. Evol. Hum. Behav. 31, 354-364. doi: 10.1016/j. evolhumbehav.2010.04.004

Klin, A., Jones, W., Schultz, R., and Volkmar, F. (2003). The enactive mind, or from actions to cognition: lessons from autism. Philos. Trans. R. Soc. Lond. B Biol. Sci. 358, 345-360. doi: 10.1098/rstb.2002.1202

Koelsch, S. (2014). Brain correlates of music-evoked emotions. Nat. Rev. Neurosci. 15, 170-180. doi: $10.1038 / \mathrm{nrn} 3666$

Kraus, N., and Strait, D. L. (2015). Emergence of biological markers of musicianship with school-based music instruction. Ann. N Y Acad. Sci. 1337, 163-169. doi: 10.1111/nyas.12631

Kraus, N., Slater, J., Thompson, E. C., Hornickel, J., Strait, D. L., Nicol, T., et al. (2014). Music enrichment programs improve the neural encoding of speech in at-risk children. J. Neurosci. 34, 11913-11918. doi: 10.1523/JNEUROSCI.188114.2014

LaGasse, A. B. (2014). Effects of a music therapy group intervention on enhancing social skills in children with autism. J. Music Ther. 51, 250-275. doi: $10.1093 / \mathrm{jmt} /$ thu012

LaGasse, A. B. (2017). Social outcomes in children with autism spectrum disorder: a review of music therapy outcomes. Patient Relat. Outcome Meas. 8, 23-32. doi: $10.2147 /$ prom.s106267
Lai, G., Pantazatos, S. P., Schneider, H., and Hirsch, J. (2012). Neural systems for speech and song in autism. Brain 135, 961-975. doi: 10.1093/brain/ awr335

Laugeson, E. A., Gantman, A., Kapp, S. K., Orenski, K., and Ellingsen, R. (2015). A randomized controlled trial to improve social skills in young adults with autism spectrum disorder: the UCLA PEERS ${ }^{\circledR}$ program. J. Autism Dev. Disord. 45, 3978-3989. doi: 10.1007/s10803-015-2504-8

Lim, H. A., and Draper, E. (2011). The effects of music therapy incorporated with applied behavior analysis verbal behavior approach for children with autism spectrum disorders. J. Music Ther. 48, 532-550. doi: 10.1093/jmt/ 48.4.532

Lord, C. R. M., DiLavore, P. C., Risi, S. Gotham, K., and Bishop, S. (2012). Autism Diagnostic Observation Schedule. 2nd Edn. Torrance, CA.: Western Psychological Services.

Ma, Y. C., Nagler, J., Lee, M. H., and Cabrera, I. N. (2001). Impact of music therapy on the communication skills of toddlers with pervasive developmental disorder. Ann. N Y Acad. Sci. 930, 445-447. doi: 10.1111/j.1749-6632.2001.tb 05766.x

Menon, V., and Levitin, D. J. (2005). The rewards of music listening: response and physiological connectivity of the mesolimbic system. Neuroimage 28, 175-184. doi: 10.1016/j.neuroimage.2005.05.053

Meyer, L. B. (1956). Emotion and Meaning in Music. Chicago, IL: University of Chicago Press.

Moreno, S., Bialystok, E., Barac, R., Schellenberg, E. G., Cepeda, N. J., and Chau, T. (2011). Short-term music training enhances verbal intelligence and executive function. Psychol. Sci. 22, 1425-1433. doi: 10.1177/0956797611416999

Mössler, K., Gold, C., Aßmus, J., Schumacher, K., Calvet, C., Reimer, S., et al. (2019). The therapeutic relationship as predictor of change in music therapy with young children with autism spectrum disorder. J. Autism Dev. Disord. 49, 2795-2809. doi: 10.1007/s10803-017-3306-y

Mottron, L., Belleville, S., Rouleau, G. A., and Collignon, O. (2014). Linking neocortical, cognitive, and genetic variability in autism with alterations of brain plasticity: the Trigger-Threshold-Target model. Neurosci. Biobehav. Rev. 47, 735-752. doi: 10.1016/j.neubiorev.2014.07.012

Mottron, L., Dawson, M., Soulières, I., Hubert, B., and Burack, J. (2006). Enhanced perceptual functioning in autism: an update and eight principles of autistic perception. J. Autism Dev. Disord. 36, 27-43. doi: 10.1007/s10803-0050040-7

Mottron, L., Peretz, I., and Ménard, E. (2000). Local and global processing of music in high-functioning persons with autism: beyond central coherence? J. Child Psychol. Psychiatry 41, 1057-1065. doi: 10.1017/s0021963099006253

Panksepp, J. (1995). The emotional sources of "chills" induced by music. Music Percept. 13, 171-207. doi: 10.2307/40285693

Patel, A. D. (2011). Why would musical training benefit the neural encoding of speech? The OPERA hypothesis. Front. Psychol. 2:142. doi: 10.3389/fpsyg.2011. 00142

Patel, A. D. (2014). Can nonlinguistic musical training change the way the brain processes speech? The expanded OPERA hypothesis. Hear. Res. 308, 98-108. doi: 10.1016/j.heares.2013.08.011

Quintin, E. M., Bhatara, A., Poissant, H., Fombonne, E., and Levitin, D. J. (2011). Emotion perception in music in high-functioning adolescents with Autism Spectrum Disorders. J. Autism Dev. Disord. 41, 1240-1255. doi: 10.1007/s10803-010-1146-0

Quintin, E. M., Bhatara, A., Poissant, H., Fombonne, E., and Levitin, D. J. (2013), Processing of musical structure by high-functioning adolescents with autism spectrum disorders. Child Neuropsychol. 19, 250-275. doi: 10.1080/09297049. 2011.653540

Rabinowitch, T. C., and Meltzoff, A. N. (2017). Joint rhythmic movement increases 4-year-old children's prosocial sharing and fairness toward peers. Front. Psychol. 8:1050. doi: 10.3389/fpsyg.2017.01050

Roberts, T. P., Khan, S. Y., Rey, M., Monroe, J. F., Cannon, K., Blaskey, L., et al. (2010). MEG detection of delayed auditory evoked responses in autism spectrum disorders: towards an imaging biomarker for autism. Autism Res. 3 , 8-18. doi: 10.1002/aur.111

Roden, I., Kreutz, G., and Bongard, S. (2012). Effects of a school-based instrumental music program on verbal and visual memory in primary school children: a longitudinal study. Front. Psychol. 3:572. doi: 10.3389/fpsyg.2012. 00572 
Rosenberg, A., Patterson, J. S., and Angelaki, D. E. (2015). A computational perspective on autism. Proc. Natl. Acad. Sci. U S A 112, 9158-9165. doi: 10.1073/pnas.1510583112

Salimpoor, V. N., Benovoy, M., Larcher, K., Dagher, A., and Zatorre, R. J. (2011). Anatomically distinct dopamine release during anticipation and experience of peak emotion to music. Nat. Neurosci. 14, 257-262. doi: 10.1038/nn.2726

Salvador, K., and Pasiali, V. (2017). Intersections between music education and music therapy: education reform, arts education, exceptionality, and policy at the local level. Arts Educ. Policy Rev. 118, 93-103. doi: 10.1080/10632913.2015. 1060553

Schellenberg, E. G. (2004). Music lessons enhance IQ. Psychol. Sci. 15, 511-514. doi: 10.1111/j.0956-7976.2004.00711.x

Schellenberg, E. G. (2011). Examining the association between music lessons and intelligence. Br. J. Psychol. 102, 283-302. doi: 10.1111/j.2044-8295.2010. 02000.x

Sharda, M., Midha, R., Malik, S., Mukerji, S., and Singh, N. C. (2015). Frontotemporal connectivity is preserved during sung but not spoken word listening, across the autism spectrum. Autism Res. 8, 174-186. doi: 10.1002/aur.1437

Sharda, M., Tuerk, C., Chowdhury, R., Jamey, K., Foster, N., CustoBlanch, M., et al. (2018). Music improves social communication and auditory-motor connectivity in children with autism. Transl. Psychiatry 8:231. doi: 10.1038/s41398-018-0287-3

Stanutz, S., Wapnick, J., and Burack, J. A. (2014). Pitch discrimination and melodic memory in children with autism spectrum disorders. Autism 18, 137-147. doi: $10.1177 / 1362361312462905$

Stephenson, K. G., Quintin, E. M., and South, M. (2016). Age-related differences in response to music-evoked emotion among childrenand adolescents with autism spectrum disorders. J. Autism Dev. Disord. 46, 1142-1151. doi: 10.1007/s10803-015-2624-1

Thompson, G. A., McFerran, K. S., and Gold, C. (2014). Family-centred music therapy to promote social engagement in young children with severe autism spectrum disorder: a randomized controlled study. Child Care Health Dev. 40, 840-852. doi: 10.1111/cch.12121

Wong, K. (1997). Neanderthal notes. Did ancient humans play modern scales?. Sci. Am. 277, 28-30. doi: 10.1038/scientificamerican0997-28

Woodbury-Smith, M., and Scherer, S. W. (2018). Progress in the genetics of autism spectrum disorder. Dev. Med. Child Neurol. 60, 445-451. doi: 10.1111/dmcn. 13717

Zaslavsky, K., Zhang, W. B., McCready, F. P., Rodrigues, D. C., Deneault, E., Loo, C., et al. (2019). SHANK2 mutations associated with autism spectrum disorder cause hyperconnectivity of human neurons. Nat. Neurosci. 22, 556-564. doi: 10.1038/s41593-019-0365-8

Conflict of Interest Statement: The author declares that the research was conducted in the absence of any commercial or financial relationships that could be construed as a potential conflict of interest.

Copyright (C) 2019 Quintin. This is an open-access article distributed under the terms of the Creative Commons Attribution License (CC BY). The use, distribution or reproduction in other forums is permitted, provided the original author(s) and the copyright owner(s) are credited and that the original publication in this journal is cited, in accordance with accepted academic practice. No use, distribution or reproduction is permitted which does not comply with these terms. 